\title{
The Phase of Iron Catalyst Nanoparticles during Carbon Nanotube Growth
}

\author{
Christoph T. Wirth ${ }^{\mathrm{a},}$, Bernhard C. Bayer ${ }^{\mathrm{a}, \$}$, Andrew D. Gamalski ${ }^{\mathrm{a}}$, \\ Santiago Esconjauregui ${ }^{\mathrm{a}}$, Robert S. Weatherup ${ }^{\mathrm{a}}$, Caterina Ducati ${ }^{\mathrm{b}}$, \\ Carsten Baehtz ${ }^{\mathrm{c}}$, John Robertson ${ }^{\mathrm{a}}$, Stephan Hofmann ${ }^{\mathrm{a}, *}$ \\ ${ }^{a}$ Department of Engineering, University of Cambridge, Cambridge CB3 OFA, UK \\ ${ }^{b}$ Department of Materials Science and Metallurgy, University of Cambridge, Cambridge CB2 3QZ, UK \\ ${ }^{\mathrm{C}}$ Institute of Ion Beam Physics and Materials Research, Helmholtz-Zentrum Dresden Rossendorf, D-01314 \\ Dresden, Germany
}

\begin{abstract}
We study the Fe-catalyzed chemical vapor deposition of carbon nanotubes by complementary in-situ grazing-incidence X-ray diffraction, in-situ X-ray reflectivity and environmental transmission electron microscopy. We find that typical oxide supported $\mathrm{Fe}$ catalyst films form widely varying mixtures of bcc and fcc phased Fe nanoparticles upon reduction, which we ascribe to variations in minor commonly present carbon contamination levels. Depending on the as-formed phase composition, different growth modes occur upon hydrocarbon exposure: For $\gamma$-rich Fe nanoparticle distributions, metallic $\mathrm{Fe}$ is the active catalyst phase, implying that carbide formation is not a prerequisite for nanotube growth. For $\alpha$-rich catalyst mixtures, $\mathrm{Fe}_{3} \mathrm{C}$ formation more readily occurs and constitutes part of the nanotube growth process. We propose that this behavior can be rationalized in terms of kinetically accessible pathways, which we discuss in the context of the bulk iron-carbon phase diagram with the inclusion of phase equilibrium lines for metastable $\mathrm{Fe}_{3} \mathrm{C}$. Our results indicate that kinetic effects dominate the complex phase evolution during realistic CNT growth recipes.
\end{abstract}

Keywords: Carbon nanotube, CVD, Fe, carbide, catalyst, XRD, ETEM

\footnotetext{
$\S$ contributed equally

* Corresponding author: email: sh315@cam.ac.uk
} 


\section{Introduction}

The unique electronic, thermal and mechanical properties of carbon nanotubes (CNTs) closely relate to the nanotube structure. In order to unlock the full application potential of CNTs, not only scalability but also structural selectivity is required for their growth. The most promising CNT growth technique is catalytic chemical vapor deposition (CVD), for which considerable progress has been made in terms of bulk production and developing processes for direct CNT device integration. ${ }^{1-3}$ This progress, however, is largely based on empirical process optimization and there remains a lack of fundamental understanding of the growth mechanisms. This critically manifests itself as lack in structural selectivity, i.e. to date selective growth of CNTs of specific chiralities remains elusive. ${ }^{4-6}$ As CNT CVD essentially relies on the self-organization of carbon on catalyst nanoparticle templates, a crucial question to be answered is what level of structural control is fundamentally achievable? This requires a much more detailed understanding of the role of the catalyst during reaction conditions, which is a common challenge throughout the field of heterogeneous catalysis. ${ }^{7}$

Here we study the phase of Fe catalyst nanoparticles during realistic CNT CVD via complementary in-situ grazing-incidence X-ray diffraction (XRD), in-situ X-ray reflectivity (XRR) and environmental transmission electron microscopy (ETEM). Fe is the archetypal catalyst material, in particular in combination with $\mathrm{Al}_{2} \mathrm{O}_{3}$ support for high yield CNT forest CVD. $^{3,8}$ A large variety of growth mechanisms have been suggested for Fe catalyzed CNT growth. ${ }^{9-31}$ Unlike to $\mathrm{Ni}$ and $\mathrm{Co}$, a range of different (meta)stable crystalline carbide phases have been reported for $\mathrm{Fe}$ upon exposure to carbonaceous precursors at elevated temperatures, ${ }^{9-13,32,33}$ but the actual nature of active Fe phases during CNT CVD and their relevance remains largely unclear. Recent ETEM $^{9,10}$ and in-situ $\mathrm{XRD}^{11,12,13}$ experiments identified cementite $\left(\theta-\mathrm{Fe}_{3} \mathrm{C}\right)$ as the active phase during CNT growth. Our data here shows that this represents only a sub-set of more complex catalyst kinetics for Fe. From repeated insitu runs we find that typical oxide supported Fe thin film catalysts form mixtures of bec $(\alpha-$ $\mathrm{Fe}$, ferrite) and fcc ( $\gamma$-Fe, austenite) phased nanoparticles upon reduction where exact phase mixtures vary between runs. We ascribe this to minor variations in adventitious carbon contamination of the catalyst films prior to hydrocarbon exposure. Depending on this phase composition, different growth modes occur: For $\gamma$-rich catalyst mixtures, we find metallic Fe is the active catalyst phase for $\mathrm{CNT}$ growth, i.e. no conversion to a carbide phase is required for CNT growth (for definition of "carbide" see footnote 34). This is in contrast to $\alpha$-rich catalyst mixtures, for which $\mathrm{Fe}_{3} \mathrm{C}$ formation is dominant and constitutes part of the CNT 
growth process. We propose that this behavior can be rationalized in terms of kinetically accessible pathways, in particular for growth temperatures close to the $\mathrm{Fe}-\mathrm{C} / \mathrm{Fe}-\mathrm{Fe} \mathrm{C}_{3}$ eutectoid temperature. Our study highlights that the widespread assumption of a global single active catalyst phase is not justified. Rather kinetic effects dictate the complex phase evolution during realistic CNT growth recipes.

\section{Experimental Section}

The in-situ diffraction experiments were performed at the BM20 beamline (Rossendorf beamline) of the European Synchrotron Radiation Facility (ESRF) in a cold-wall reactor chamber (base pressure $10^{-5}$ mbar) mounted onto a high-precision 6-circle goniometer. ${ }^{35-37}$ The chamber is equipped with a hemispherical Be-dome to allow transmission of the X-rays in different scattering geometries. We use a resistive heater (Boralectric) for sample heating and in-built and sample surface-clamped thermocouples to monitor and regulate temperature. High purity process gases $\left(\mathrm{Ar}, \mathrm{H}_{2}, \mathrm{C}_{2} \mathrm{H}_{2}\right)$ are introduced via separate mass flow controllers.

The energy of the X-rays is selected by a $\operatorname{Si}\left(\begin{array}{lll}1 & 1 & 1\end{array}\right)$ double crystal monochromator. We use a monochromatic X-ray beam of $11.5 \mathrm{keV}$ with a corresponding wavelength of $1.078 \AA$. The diffracted X-rays are measured with a scintillation detector. A horizontally aligned Soller slit system is used for grazing incidence (GI) XRD experiments with an incident angle of $\alpha_{\mathrm{i}}=0.5^{\circ}$ and a slit system for XRR measurements, respectively.

As standard substrate, we use $\mathrm{Si}\left(\begin{array}{lll}1 & 0 & 0\end{array}\right)$ wafers covered with $200 \mathrm{~nm}$ of thermal $\mathrm{SiO}_{2}$. One set of samples is further covered with a sputter deposited $10 \mathrm{~nm}$ thick $\mathrm{Al}_{2} \mathrm{O}_{3}$ layer. Onto both $\mathrm{SiO}_{2}$ and $\mathrm{Al}_{2} \mathrm{O}_{3}$ supports a $8 \mathrm{~nm}$ thick Fe film is thermally evaporated. The relatively thick catalyst layer is required to obtain acceptable XRD counting rates. We note that for such thick Fe films we do not observe any significant differences between the $\mathrm{SiO}_{2}$ and $\mathrm{Al}_{2} \mathrm{O}_{3}$ supports in the XRR/XRD results or regarding the CNT yield.

Samples are processed according to the CVD steps summarized in Figure 1. After characterization of the as deposited catalyst film at room temperature (I), the sample is annealed in an $\mathrm{Ar}: \mathrm{H}_{2}(30: 10 \mathrm{sccm})$ atmosphere at $\sim 150 \mathrm{mbar}$ at $750^{\circ} \mathrm{C}$ (II). For CNT growth, we add $\mathrm{C}_{2} \mathrm{H}_{2}(1 \mathrm{sccm})$ to the $\mathrm{Ar}: \mathrm{H}_{2}$ gas flow (III). After CNT CVD, the chamber is pumped out and the sample is left to cool in vacuum (IV). The samples are characterized by in-situ GIXRD during each process step to determinate the crystalline phases. A scan typically takes $\sim 20 \mathrm{~min}$. Note that between step I and II, as well as between steps III and IV, the position of 
reflections shifts due to thermal expansion. A series of 12 samples was measured under nominally constant CVD conditions. In-situ XRR measurements were additionally performed on selected samples.

Qualitative phase identification from the XRD data is based on the following International Center for Diffraction Data (ICDD) powder diffraction files: $\alpha$-Fe: 06-0696; $\gamma$-Fe: $65-4150$; cementite $\theta-\mathrm{Fe}_{3} \mathrm{C}$ : 35-0772; graphite: 41-1487; Fe-oxides: 33-0664, 89-7100, 19-0629, 39$1346 .{ }^{38}$ Rietveld refinement (X'Pert Plus) was employed for all XRD scans after removal of the broad background features from the amorphous support via comparison to bare supports. Due to the limited signal-to-noise quality of our XRD data, a conservative refinement strategy was employed where only the following parameters were refined: 1 . scale factors for all phases, 2. flat background with 1 coefficient, 3. zero shift, 4. lattice parameters, 5. additional background with 2 more coefficients, 6. halfwidth for all phases (peak shape is fixed to Pseudo-Voigt). For Rietveld refinement the following Inorganic Crystal Structure Database (ICSD) entries were used: $\alpha$-Fe: 53451, $\gamma$-Fe: 44862, cementite $\theta-\mathrm{Fe}_{3} \mathrm{C}: 99020$, Haegg-carbide $\chi-\mathrm{Fe}_{5} \mathrm{C}_{2}: 89328$, hexagonal $\varepsilon-\mathrm{Fe}_{3} \mathrm{C}: 44354, \eta-\mathrm{Fe}_{2} \mathrm{C}: 87128$, Eckstroem-Adock carbide $\mathrm{Fe}_{7} \mathrm{C}_{3}: 31018,76830$ (see also footnote 39 ). We estimate an uncertainty of $\sim \pm 5 \mathrm{wt}-\%$ for the obtained phase compositions (see also footnote 40).

ETEM experiments were carried out in a modified FEI Tecnai F20 equipped with a differential pumping system. Bright field images were recorded with an Orius digital video camera recorded at 9 frames $\mathrm{s}^{-1}$ time resolution. Temperature was measured via a thermocouple located on the single tilt Gatan Inconel heated sample holder. Electron doses were comparable to typical high resolution bright field imaging. Samples were prepared by thermally evaporating $0.7 \mathrm{~nm}$ Fe onto $\mathrm{SiO}_{\mathrm{x}}$-covered Mo-TEM grids. The samples were lamp heated in air for $30 \mathrm{~min}$ prior to loading into the ETEM. Before CNT growth, the samples were treated in 1.3 mbar of $\mathrm{NH}_{3}$ at $650{ }^{\circ} \mathrm{C}$ for 1 hour. It was however found that the low pressure $\mathrm{NH}_{3}$ treatment was not sufficient to reduce the oxidized Fe catalyst. For CNT growth, undiluted $\mathrm{C}_{2} \mathrm{H}_{2}$ was introduced at a pressure of $\sim 10^{-2}$ mbar. See supporting information for a summary of the TEM phase identification.

Additional ex-situ sample characterization was carried out by scanning electron microscopy (SEM, Philips x130) and by high resolution (HR)-TEM (FEI Tecnai F20, 200 $\mathrm{kV}$ ). 


\section{Results}

We adopt a simple one-step annealing process as the model CVD recipe and keep a consistent nomenclature for the process steps as outlined in Figure 1. Figures 2-4 show insitu, process-resolved XRD data representative of a series of 12 in-situ XRD growth runs, all for a CVD temperature of $750^{\circ} \mathrm{C}$ and a nominally $8 \mathrm{~nm}$-thick Fe catalyst film on oxide support. From these repeated in-situ runs, we found variations in the phase evolution, where in Figures 2-4 we highlight three characteristic cases.

The first typical evolution in Figure 2a shows the as-deposited films to be composed of nano-sized $\alpha$-Fe crystallites. A broad reflection around $24-25^{\circ}$ indicates the presence of a poorly crystallized Fe-oxide layer due to the air exposure during sample storage/transfer, which is additionally confirmed by X-ray reflectivity (XRR) measurements (Supplementary Figure $\mathrm{S} 1$ ). Upon heating in $\mathrm{H}_{2}$ this amorphous oxide layer is reduced, as shown by the disappearance of both the corresponding oscillations in the XRR and of the broad $24-25^{\circ}$ XRD reflection. Concurrently the Fe film splits into nanoparticles, as observed by XRR and SEM (Supplementary Figure S1). During heating (step II), a mixture of $\alpha$-Fe and $\gamma$-Fe evolves, for which we estimate the phase composition by Rietveld refinement. For the case exemplified in Figure 2a, initially more $\gamma$-Fe is present at stage II. Upon $\mathrm{C}_{2} \mathrm{H}_{2}$ introduction, CNT growth manifests itself by the appearance of a graphite-related reflection at $\sim 18^{\circ}$. The mixture of Fe phases shows a very dynamic behavior during this stage, where now $\alpha$-Fe becomes the slightly more dominant phase (stage III, Figure 2a). Most notably, no carbide reflections are observed during the $\mathrm{C}_{2} \mathrm{H}_{2}$ exposure or after $\mathrm{CVD}$, implying that carbide formation is not a prerequisite for CNT growth (see also footnotes 34 and 40).

Figures 3 and 4 show a different catalyst evolution for nominally similar samples and CVD conditions. For the evolution type in Figure $3 \mathrm{a}$ the initial $\alpha$-Fe transforms under heating in $\mathrm{H}_{2}$ to a $\alpha / \gamma$ mixture with the reduction of an initial oxide layer, as in Figure 2. During $\mathrm{C}_{2} \mathrm{H}_{2}$ exposure, however, $\gamma$-Fe becomes dominant ( $\sim 84 \mathrm{wt}-\%$, stage III), and remains so after cooling (stage IV, Figure 3a). Again no Fe carbide reflections are observed.

In the third exemplified case (Figure $4 \mathrm{a}$ ) the initial $\alpha$-Fe phase is retained during annealing in $\mathrm{H}_{2}$, with only a very small contribution of $\gamma$-Fe evolving. During subsequent $\mathrm{C}_{2} \mathrm{H}_{2}$ exposure, reflections corresponding to a Fe-carbide clearly emerge as well as the graphiterelated reflection at $\sim 18^{\circ}$. The carbide becomes the most dominant phase ( $\sim 65 \mathrm{wt}-\%$, stage III, Figure 4a), with the apparent conversion of $\alpha$-Fe. Both the qualitative phase analysis and the Rietveld refinement (Figure 5a) show that the emergent carbide reflection pattern is best 
matched by cementite ( $\mathrm{Fe}_{3} \mathrm{C}$, see also footnote 39$)$. Upon cooling the phase mixture of $\alpha$-Fe, $\gamma$-Fe and iron carbide is approximately preserved (Figure 4a, stage IV).

The ex-situ, post-growth SEM analysis clearly confirms CNT growth for all samples (Figures $2 \mathrm{~b}, 3 \mathrm{~b}, 4 \mathrm{~b}$ ). The as-grown CNTs are for all samples predominantly multi-walled, mixed with some bamboo-type structures and graphite-cage encapsulated catalyst particles (see TEM in Supplementary Figure S2). The overall CNT yield and diameter distributions are similar for the repeated in-situ runs and the different observed catalyst phase evolutions. For instance, the sample corresponding to Figure 3 (predominantly $\gamma$-Fe at stage III) has an average tube diameter of $26 \mathrm{~nm}$ (standard deviation of $11 \mathrm{~nm}$; $\min : 9 \mathrm{~nm}$, max: $50 \mathrm{~nm}$ ). The sample from the different phase evolution in Figure 4 (carbide formation at stage III) shows a very similar average diameter of $24 \mathrm{~nm}$ (standard deviation of $9 \mathrm{~nm}$; $\min : 11 \mathrm{~nm}$, max: 49 $\mathrm{nm}$ ). The phases of active nanoparticles found in the ex-situ TEM analysis (Figures 3c, 4c) are consistent with the corresponding XRD results at stage IV. The multi-walled, partly defective nature of the as-grown CNTs does not allow us to comment in more detail on statistically relevant differences in the CNT structures resulting from the different catalyst phase mixtures.

We emphasize that the three cases in Figures 2-4 are the typical evolution types that we have repeatedly observed over the course of 12 in-situ experiments under nominally constant CVD conditions. These three types can be loosely grouped based on the catalyst phase mixture during stage III: Figure 2 represents a mixed-metallic $(\alpha-\mathrm{Fe} / \gamma-\mathrm{Fe})$ state, Figure 3 a pre-dominant $\gamma$-Fe catalyst state, while Figure 4 represents a pre-dominant carbide type evolution. Summarizing over all 12 in-situ runs, Figure $5 \mathrm{~b}$ highlights the statistical trends in the estimated phase composition at salient CVD stages for these three grouped cases. For high $\gamma$-Fe content and equi-percentile $\alpha / \gamma$-mixtures at stage II, we observe a "metallic route" without carbide formation (corresponding to Figures 2 and 3). On the other hand, for high $\alpha$ Fe phase abundances at stage II, we find that the "carbide route" occurs (Figure 4). Figure 5e schematically summarizes these reaction pathways.

The in-situ XRD signal is an integral, representing many catalyst particles. In order to go beyond the limited interpretation of such integral probing of heterogeneous samples, we use ETEM to obtain complementary, lattice-resolved information of individual nanoparticles for Fe-catalysed CNT CVD. Figure 6 shows representative ETEM image sequences of isolated Fe particles upon exposure to $\mathrm{C}_{2} \mathrm{H}_{2}$ at $650^{\circ} \mathrm{C}$ (see Supporting Information videos V1 and V2, corresponding to Figures $6 \mathrm{a}$ and $6 \mathrm{~b}$, respectively). The initial Fe film thickness thereby was $0.7 \mathrm{~nm}$. Consistent with our prior data on $\mathrm{Ni}^{18}{ }^{18}$ the particles are solid, exhibiting crystalline 
lattice fringe contrast at any stage of the growth process. Most particles are initially oxidized (see also footnote 41), displaying a highly faceted geometry (Figure 6a, 0s). For most frames, only one set of lattice fringes is visible, which makes their assignment ambiguous. The 0.25 $\mathrm{nm}$ spacing measured in Figure $6 \mathrm{a}$ at $0 \mathrm{~s}$ can be best assigned to $\{110\}$ lattice planes in $\mathrm{Fe}_{2} \mathrm{O}_{3}$ (hematite). The frame sequence of Figure 6a shows in detail how the oxide crystal gradually reduces, starting from the lower right, whereby the reduced metallic nucleus assumes a more spherical shape. At the end of the image sequence, a $0.24 \mathrm{~nm}$ spacing is visible (Figure 6a at $13 \mathrm{~s}$, and FFT inset) which may correspond to the $\{2-10\}$ family of reflections in $\mathrm{Fe}_{3} \mathrm{C}$. The observation of cementite during the heating of iron oxide nanocrystals in $\mathrm{C}_{2} \mathrm{H}_{2}$ is consistent with previous ETEM experiments in similar conditions. ${ }^{10}$ The ETEM image sequence in Figure $6 \mathrm{~b}$ shows how a CNT nucleates via the lift-off of a carbon cap from a reduced Fe particle (see supporting information video V2). The observed $0.21 \mathrm{~nm}$ reflection measured from the FFT (inset, Figure $6 \mathrm{~b}$ at $4.9 \mathrm{~s}$ ) is consistent with either an iron metal or carbide phase. It is important to notice that for highly symmetric crystal structures such as fcc and bcc Fe the diffraction conditions are much more stringent than for lower symmetry crystal structures, such as the orthorhombic $\mathrm{Fe}_{3} \mathrm{C}$. Therefore there is a limited range of crystal orientations that would allow an unambiguous identification of metallic Fe in ETEM, which prevents us here from presenting a statistical analysis of the active phase of the Fe catalyst during ETEM-based CNT growth. Figure $6 \mathrm{~b}$ shows that the initial diameter of the carbon cap is smaller than that of the catalyst particle, similar to Ni catalyzed CNT nucleation. ${ }^{18}$ The cap diameter then increases to roughly match the Fe particle's diameter, which itself restructures heavily during the process. 


\section{Discussion}

The combination of our XRD and ETEM data confirms that the catalyst bulk is crystalline during nanotube growth under our CVD conditions. The XRD data in Figures 2 and 3 shows that the formation of a crystalline carbide nanoparticle phase is not a prerequisite for nanotube growth. The XRD data in Figure 4 however suggests that carbide nanoparticles can also act as CNT catalysts (also implied by the ETEM and previous literature ${ }^{9-13}$ ). The question that arises from this data is why we observe varying phase mixtures for nominally similar CVD conditions during our repeated in-situ XRD experiments.

First, we suggest that the surprising appearance of non-equilibrium $\gamma$-Fe in the nominally pure Fe catalyst prior to the carbon precursor exposure (stage II) at temperatures below $912^{\circ} \mathrm{C}$ (see Fe-C phase diagram in Figure 7; compared to our in-situ XRD CVD at $750^{\circ} \mathrm{C}$ ) can be explained by the unavoidable presence of residual carbon contamination from catalyst preparation, air transfer, and/or the CVD reactor (confirmed on as-prepared catalyst films by $\mathrm{X}$-ray photoelectron spectroscopy). This adventitious carbon can dissolve into the Fe during annealing (stage II). This shifts the system to the right of pure Fe in the phase diagram in Figure 7 , thus enabling $\gamma$-Fe nucleation below $912^{\circ} \mathrm{C}$. As the amount of this residual carbon contamination varies within certain limits between samples/runs (indicated by the shaded vertical region on the left hand side of Figure 7 ), this accounts for the varying $\gamma-/ \alpha$-Fe ratios during pre-treatment (stage II).

Second, the observed phase behavior upon growth (stage III) can then be rationalized via the bulk Fe-C phase diagram with the inclusion of phase equilibrium lines for metastable $\mathrm{Fe}_{3} \mathrm{C}$ (Figure 7). ${ }^{42,43}$ It is crucial to note that our in-situ XRD CVD temperature of $750^{\circ} \mathrm{C}$ is very close to the eutectoid temperatures for $\mathrm{Fe}-\mathrm{C}\left(740^{\circ} \mathrm{C}\right)$ and $\mathrm{Fe}-\mathrm{Fe} 3 \mathrm{C}\left(727^{\circ} \mathrm{C}\right)$. In this transition region the formation of a new phase is strongly dependent upon nucleation barriers. This is due to the statistical nature of nucleation, whereby the nucleation rate $I$ is determined by the magnitude of the nucleation barrier $\Delta G^{*}$ (Eqn. 1)

$$
I \propto \exp \left[-\Delta G^{*} /\left(k_{\mathrm{B}} T\right)\right]
$$

Eqn. 1

where $k_{\mathrm{B}}$ is Boltzmann's constant and $T$ is the temperature. ${ }^{44}$ The catalyst evolution during CVD around this temperature will therefore be much more influenced by nucleation kinetics than by thermodynamics. 
We relate this argument to our observations using the two limiting isothermal process pathways that are schematically indicated in Figure 7: one pathway slightly above $(A)$ and one slightly below $(B)$ the eutectoid temperature. Upon isothermal acetylene exposure the $\alpha$ $/ \gamma$-Fe mixtures from stage II saturate with carbon. For process $A$, the pathway will intersect at point $a_{1}$, where $\alpha-\mathrm{Fe}$ and $\gamma-\mathrm{Fe}$ are in equilibrium and to the right of which the nucleation barrier to form $\gamma$-Fe falls (because progressively larger carbon super-saturations result in a smaller $\Delta G^{*}$ value and consequently a higher nucleation rate $I$ ). Since the $\alpha-\mathrm{Fe} / \gamma-\mathrm{Fe}$ coexistence line $\left(a_{1}\right)$ is passed before the extrapolated $\alpha-\mathrm{Fe} / \mathrm{Fe}_{3} \mathrm{C}$ line (point $a_{2}$ ), preferential nucleation of $\gamma$-Fe rather than carbide formation is expected. Once $\gamma$-Fe has formed, the carbon composition in the system continues to rise until intersecting the $\gamma$-Fe/C coexistence line, point $a_{4}$. At carbon compositions to the right of $a_{4}$, i.e. upon carbon super-saturation of the $\gamma$-Fe particle, CNT nucleation will occur and growth will proceed directly from $\gamma$-Fe. It is important to note that pathway $A$ intersects the $\gamma$-Fe/C equilibrium line $\left(a_{4}\right)$ before the $\gamma$ $\mathrm{Fe} / \mathrm{Fe}_{3} \mathrm{C}$ solidus $\left(a_{5}\right)$ which is only reached at a carbon content $\sim 0.5$ atom- $\%$ higher. This large difference $\Delta \chi_{\mathrm{a}}$ indicates that a $\gamma$-Fe catalyst should be stable against $\mathrm{Fe}_{3} \mathrm{C}$ nucleation. The growing CNT provides a sink for excess carbon and keeps the $\gamma$-Fe catalyst close to $a_{4}$, effectively preventing the nucleation of a carbide catalyst which would occur to the right of a5. This is consistent with our experimental observation that for initial high $\gamma$-Fe containing mixtures we observe nanotube growth without the formation of Fe-carbide.

In contrast, for pathway $B$, the compositional difference $\Delta \chi_{\mathrm{b}}$ between the $\alpha-\mathrm{Fe} / \mathrm{C}$ and $\alpha-$ $\mathrm{Fe} / \mathrm{Fe}_{3} \mathrm{C}$ coexistence lines is much smaller $\left(\sim 0.01\right.$ atom-\%). Thus, $\mathrm{Fe}_{3} \mathrm{C}$ nucleation is much easier to achieve (crossing $b_{2}$ ) for a given carbon supersaturation. After nucleating a carbide close to $b_{2}$, CNT growth from a carbide catalyst would occur. This is consistent with the observation that for $\alpha$-Fe-rich mixtures we observe carbide formation concurrent to nanotube growth.

Close to the eutectoid temperature, the observation of metal and carbide catalyzed CNT CVD indicates that in this region the nucleation rates of $\gamma$-Fe $\left(I_{\gamma}\right)$ and the carbide $\left(I_{c}\right)$ are of the same order of magnitude and kinetic effects dominate over the equilibrium phase diagram in this region (indicated by the shaded horizontal region in Figure 7). Only at temperatures far above and far below the eutectoid temperature would we expect CNT growth to be dominated by mostly metallic $\left(I_{\gamma}>>I_{c}\right)$ and carbide $\left(I_{\gamma}<<I_{c}\right)$ catalysts, respectively (see also footnote 45). This is also generally consistent with our ETEM data at $650{ }^{\circ} \mathrm{C}$ and with previous ETEM reports at $600-650^{\circ} \mathrm{C} .^{9,10}$ 
We note that effects of particle size, ${ }^{46-49}$ catalyst support ${ }^{8,22}$ and further residual and process gases (e.g. N, O, $\mathrm{H}_{2} \mathrm{O}$ etc. ${ }^{3,20}$ ) may also be of importance but are not needed to account for the major findings here (see also footnote 50). Instead, we identified the two key processes that lead to the observed statistical variation between repeated in-situ runs: 1 . Varying residual carbon contamination between runs leads to varying $\alpha-\mathrm{Fe} / \gamma-\mathrm{Fe}$ mixtures upon annealing (stage II) and 2. these mixtures then further evolve upon isothermal carbon uptake in a kinetic manner governed by the statistics of phase nucleation. Our results thus indicate that subtle influences (such as minor residual carbon), which are always present in realistic CNT growth recipes, can dramatically affect the kinetic pathways that the catalyst evolution in nanoscale systems follows.

\section{Conclusions}

In summary, our in-situ data shows that oxide supported Fe nanoparticle distributions show a varying $\gamma / \alpha$ phase mixture upon annealing, which we attribute to the practically unavoidable residual carbon contamination present in standard CVD reactors and airtransferred samples. These phase mixtures then further evolve upon isothermal carbon exposure in a kinetic manner governed by the statistics of phase nucleation. For $\gamma$-rich $\mathrm{Fe}$ nanoparticle distributions, we find metallic Fe as the main active catalyst phase for CNT growth, implying that carbide formation is not a prerequisite for nanotube growth. This is unlike $\alpha$-rich $\mathrm{Fe}$ nanoparticle distributions, for which $\mathrm{Fe}_{3} \mathrm{C}$ formation is dominant and constitutes part of the CNT growth process. Our results indicate that kinetic effects dominate the catalyst phase evolution for common CNT CVD. This is similar to our recent findings on catalytic nanowire CVD, ${ }^{51,52}$ suggesting that non-equilibrium catalyst phases are of general importance for such crystal growth on the nano-scale. 


\section{Acknowledgments}

S.H. acknowledges funding from ERC grant InsituNANO (n²79342). We acknowledge the European Synchrotron Radiation Facility (ESRF) for provision of synchrotron radiation facilities. We acknowledge the use of facilities within the LeRoy Eyring Center for Solid State Science at Arizona State University. C.T.W. and C.S.E. acknowledge funding from the EC project Technotubes. A.D.G. acknowledges funding from the Marshall Aid Commemoration Commission and the National Science Foundation. R.S.W. acknowledges funding from EPSRC (Doctoral training award) and B.C.B. acknowledges a Research Fellowship at Hughes Hall, Cambridge.

\section{Supporting Information Available}

Additional in-situ X-ray reflectivity (XRR) measurements and SEM images of catalyst particles for stage II (annealing). Further TEM images of the carbon deposits and general comments on TEM assignment. ETEM videos V1 and V2 corresponding to Figures 6a and $6 \mathrm{~b}$, respectively. This material is available free of charge via the Internet at http://pubs.acs.org. 


\section{References and Footnotes}

Tessonnier, J.-P.; Su, D. S. ChemSusChem 2011, 4, 824-847.

2 Dai, H.; Rinzler, A. G.; Nikolaev, P.; Thess, A.; Colbert, D. T.; Smalley, R. E. Chem. Phys. Lett. 1996, 260, 471-475.

3 Hata K.; Futaba D. N.; Mizuno K.; Namai T.; Yumura M.; Iijima S. Science 2004, 306, $1362-1364$

4 Harutyunyan, A. R.; Chen, G.; Paronyan, T. M.; Pigos, E. M.; Kuznetsov, O. A.; Hewaparakrama, K.; Kim, S. M.; Zakharov, D.; Stach, E. A.; Sumanasekera, G. U. Science 2009, 326, 116-120.

5 Rao, R.; Liptak, D.; Cherukuri, T.; Yakobson, B. I.; Maruyama, B. Nat. Mater. 2012, 11, 213-216.

6 Fouquet, M.; Bayer, B. C.; Esconjauregui, S.; Blume, R.; Warner, J. H.; Hofmann, S.; Schlögl, R.; Thomsen, C.; Robertson J. Phys. Rev. B 2012, 85, 235411.

7 Stierle, A.; Molenbroek, A. M. MRS Bull. 2007, 32, 1001-1005.

8 Mattevi, C.; Wirth, C. T.; Hofmann, S.; Blume, R.; Cantoro, M.; Ducati, C.; Cepek, C.; Knop-Gericke, A.; Milne, S.; Castellarin-Cudia, C.; Dolafi, S.; Goldoni, A.; Schloegl, R.; Robertson, J. J. Phys. Chem. C 2008, 112, 12207-12213.

9 Yoshida, H.; Takeda, S.; Uchiyama, T.; Kohno, H.; Homma, Y. Nano Lett. 2008, 8, 20822086

10 Sharma, R.; Moore, E.; Rez, P.; Treacy, M. M. J. Nano Lett. 2009, 9, 689-694.

11 Nishimura, K.; Okazaki, N.; Pan, L. J.; Nakayama, Y. Jpn. J. Appl. Phys. 2004, 43, L471L474.

12 Emmenegger, C.; Bonard, J.-M.; Mauron, P.; Sudan, P.; Lepora, A.; Grobety, B.; Zuttel, A.; Schlapbach, L. Carbon 2003, 41, 539-547.

13 Landois, P.; Rouziere, S.; Pinault, M.; Porterat, D.; Mocuta, C.; Elkaim, E.; MayneL'Hermite, M.; Launois, P. Phys. Status Solidi B 2011, 248, 2449-2453.

Baker, R. T. K.; Harris, P. S.; Thomas, R. B.; Waite, R. J. J. Catal. 1973, 30, 86-95.

De Bokx, P. K.; Kock, A. J. H. M.; Boellaard, E.; Klop, W.; Geus, J. W. J. Catal. 1985, $96,54-467$.

Baker, R. T. K.; Alonzo, J. R.; Dumesic, J. A.; Yates, D. J. C. J. Catal. 1982, 77, 74-84.

17 Rodrigues-Manzo, J.A.; Terrones, M.; Terrones, H.; Kroto, H.; Sun, L.; Banhart, F. Nat. Nanotechnol. 2007, 2, 307-311. 
Hofmann, S.; Sharma, R.; Ducati, C.; Du, G.; Mattevi, C.; Cepek, C. ; Cantoro, M.; Pisana, S.; Parvez, A.; Cervantes-Sodi, F. ; Ferrari, A. C.; Dunin-Borkowski, R.; Lizzit, S.; Petaccia, L.; Goldoni, A.; Robertson, J. Nano Lett. 2007, 7, 602-608.

19 Hofmann, S.; Blume, R.; Wirth, C. T.; Cantoro, M.; Sharma, R.; Ducati, C.; Hävecker, M.; Zafeiratos, S.; Schnoerch, P.; Oesterreich, A.; Teschner, D.; Albrecht, M.; KnopGericke, A.; Schlögl, R.; Robertson, J. J. Phys. Chem. C. 2009, 113, 1648-1656.

Ducati, C.; Koziol, K.; Friedrichs, S.; Yates, T. J. V.; Shaffer, M. S.; Midgley, P. A.; Windle, A. H. Small 2006, 2, 774-784.

Schaper, A. K.; Hou, H.; Greiner, A.; Phillipp, F. J. Catal. 2004, 222, 250-254.

Philippe, R.; Caussat, B.; Falqui, A.; Kihn, Y.; Kalck, P.; Bordere, S.; Plee, D.; Gaillard,, P.; Bernard, D.; Serp, P. J. Catal. 2009, 263, 345-358.

He, Z.; Maurice, J.-L.; Gohier, A.; Lee, C. S.; Pribat, D.; Cojocaru, C. S. Chem. Mater. 2011, 23, 5379-5387.

Homma, Y.; Kobayashi, Y.; Ogino, T.; Takagi, D.; Ito, R.; Jung, Y. J.; Ajayan, P. M. J. Phys. Chem. B 2003, 107, 12161-12164.

Kim, S. M.; Pint, C. L.; Amama, P. L.; Zakharov, D. N.; Hauge, R. H.; Maruyama, B.; Stach, E. A. J. Phys. Chem. Lett. 2010, 1, 918-922.

Heresanu, V.; Castro, C.; Cambedouzou, J.; Pinault, M.; Stephan, O.; Reynaud, C.; Mayne-L'Hermite, M.; Launois, P. J. Phys. Chem. C 2008, 112, 7371-7378.

Harutyunyan, A. R.; Mora, E.; Tokune, T.; Bolton, K.; Rosen, A.; Jiang, A.; Awasthi, N.; Curtarolo, S. Appl. Phys. Lett. 2007, 90, 163120.

Kim, H.; Sigmund, W., Carbon 2005, 43, 1743-1748.

Anisimov, A. S.; Nasibulin, A. G.; Jiang, H.; Launois, P.; Cambedouzou, J.; Shankdakov, S. D.; Kauppinen, E. I. Carbon 2010, 48, 380-388.

Ohta, Y.; Okamoto, Y.; Page, A. J.; Irle, S.; Morokuma, K. ACS Nano 2009, 3, 34133420 .

Page, A. J.; Yamane, H.; Ohta, Y.; Irle, S.; Morokuma, K. J. Am. Chem. Soc. 2010, 132, 15699-15707.

Herranz, T.; Rojas, S.; Perez-Alonso, F. J.; Ojeda, M.; Terreros, P.; Fierro, J. L. G. J. Catal. 2006, 243, 199-211.

du Plessis, H. E.; de Villiers, J. P. R.; Kruger, G. J.; Steuwer, A.; Brunelli, M. J. Synchrotron Rad. 2011, 18, 266-271.

There is a certain ambiguity in the literature which Fe-carbon compounds are called "Fecarbides". Therefore we clarify our use here: We understand in this study a carbide as a 
crystallographically defined bulk Fe-C compound (this includes the well known carbide phases Haegg-carbide $\chi$-Fe ${ }_{5} \mathrm{C}_{2}$, hexagonal $\varepsilon$-Fe ${ }_{3} \mathrm{C}, \eta-\mathrm{Fe}_{2} \mathrm{C}$, Eckstroem-Adock carbide $\mathrm{Fe}_{7} \mathrm{C}_{3}$ and cementite $\mathrm{Fe}_{3} \mathrm{C}$ ), which is also justified by the nature of XRD and ETEM as structural bulk probes. This definition does however not include surface carbides (ordered Fe-C surface reconstructions and Fe-C surface layers) and also not bulk Fe-C solid solutions (crystalline Fe particle with carbon dissolved into interstitial positions ${ }^{53}$ ). Thus the observation of a metallic growth route in our study does by no means exclude the formation of a Fe-C solid-solution and/or Fe-C surface reconstruction, whereas we can clearly exclude that the formation of a crystalline bulk Fe-carbide particle is a necessity for nanotube growth.

Weatherup, R. S.; Bayer, B. C.; Blume, R.; Ducati, C.; Baehtz, C.; Schlögl, R.; Hofmann, S. Nano Lett. 2011, 11, 4154-4160.

Bayer, B. C.; Zhang, C.; Blume, R.; Yan, F.; Fouquet, M.; Wirth, C. T.; Weatherup, R. S.; Lin, L.; Baehtz, C.; Oliver, R. A.; Knop-Gericke, A.; Schlögl, R.; Hofmann, S.; Robertson J. J. Appl. Phys. 2011, 109, 114314.

Bayer, B. C.; Hofmann, S.; Castellarin-Cudia, C.; Blume, R.; Baehtz, C.; Esconjauregui, S.; Wirth, C. T.; Oliver, R. A.; Ducati, C.; Knop-Gericke, A.; Schlögl, R.; Goldoni, A.; Cepek, C.; Robertson J. J. Phys. Chem. C 2011, 115, 4359-4369.

Note that for all XRD-measured samples we can exclude the formation of martensite (ICDD 44-1289, 441291) upon cooling, since we have not observed any corresponding reflection splitting or significant reflection broadening from step III to step IV.

We note that the reflection patterns for the various Fe-carbides are so similar that with our data we cannot identify the carbide phase as cementite $\theta-\mathrm{Fe}_{3} \mathrm{C}$ with absolute certainty. The * indexed reflection pattern in Figure 4a also partially matches other carbides such as Haegg-carbide $\chi$ - $\mathrm{Fe}_{5} \mathrm{C}_{2}$, hexagonal $\varepsilon-\mathrm{Fe}_{3} \mathrm{C}, \eta-\mathrm{Fe}_{2} \mathrm{C}$ and Eckstroem-Adock carbide $\mathrm{Fe}_{7} \mathrm{C}_{3}$ or a mixture thereof. We note, however, that both in terms of qualitative analysis and Rietveld refinement cementite $\mathrm{Fe}_{3} \mathrm{C}$ gives the best match for our data.

40 Even when forcing a carbide contribution into the Rietveld refinement for scans which are assigned as pure metal, we can only obtain a maximum phase contribution of $\sim 5 \mathrm{wt}-$ $\%$. However, already for such low values the quality of the fits is reduced significantly (or the fits do not even converge), indicating that our conclusion is valid that there is no carbide present in the thus assigned purely metallic samples. On this basis we can estimate an upper bound for a hidden carbide phase in the data/noise a to a maximum contribution of $\sim 5 \mathrm{wt}-\%$. 
The thin ETEM samples were lamp heated in air for $30 \mathrm{~min}$ prior to loading into experimentation, and this accounts for the different degree of oxidation compared to the thicker XRD samples that were not lamp heated. situ XRD measurements result in particle/CNT diameters larger than $10 \mathrm{~nm}$ (see Supplementary Figure S1). For such large particles changes in the phase diagram due to size-related effects are typically found to be negligible. ${ }^{54} \mathrm{We}$ also again emphasize that for these thick Fe films we do not observe significant differences between $\mathrm{SiO}_{2}$ and $\mathrm{Al}_{2} \mathrm{O}_{3}$ supports in $\mathrm{CNT}$ yield or XRR and XRD results for Fe. Most importantly, for both supports both the metallic and the carbide routes were observed in repeated runs.

51 Gamalski, A. D.; Tersoff, J.; Sharma, R.; Ducati, C.; Hofmann, S. Nano Lett. 2010, 10, 2972-2976.

52 Gamalski, A. D.; Tersoff, J.; Sharma, R.; Ducati, C. ; Hofmann, S. Phys. Rev. Lett., 2012, $108,255702$.

Rinaldi, A.; Tessonnier, J.-P.; Schuster, M. E.; Blume, R.; Girgsdies, F.; Zhang, Q.; Jacob, F.; Hamid, S. B. A.; Su, D. S.; Schlögl, R. Angew. Chem. Int. Ed. 2011, 50, 3313-3317. 


\section{Figures}

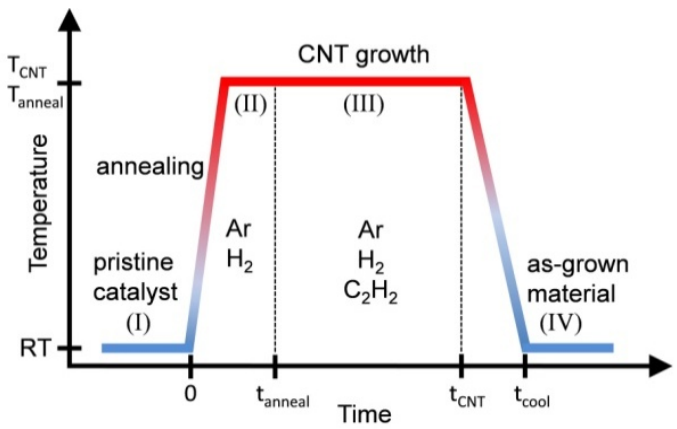

Figure 1: Schematic of the CVD process. In-situ XRD characterization was performed during each step: (I) as deposited catalyst, (II) pre-treatment/annealing, (III) CNT growth, (IV) after CVD (cooled to room temperature, RT). $\mathrm{T}_{\text {anneal }}$ and $\mathrm{T}_{\mathrm{CNT}}$ were $750^{\circ} \mathrm{C}$ for the in-situ XRD. 


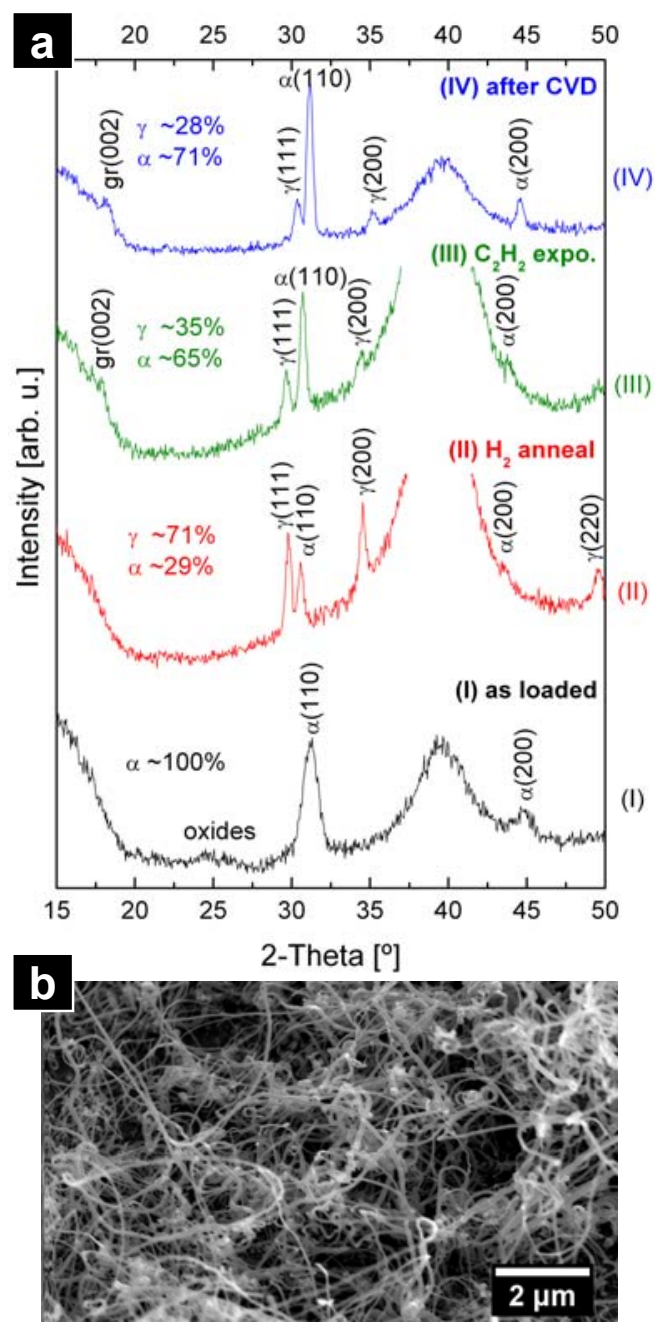

Figure 2: In-situ diffractograms for each CVD process step (I-IV). Only metallic Fe is detected during the salient stages of growth. ("gr" designates reflections from graphitic material, " $\alpha$ " from $\alpha-\mathrm{Fe}$ and " $\gamma$ " from $\gamma$-Fe.) The percentages indicate the phase composition in weight-\%, as obtained from Rietveld refinement of the XRD scans. The broad background flanks towards $15^{\circ}$ and towards $55^{\circ}$ and the broad hump around $40^{\circ}$ are due to diffuse scattering from the amorphous support (same in Figures 3 and 4). This amorphous background is getting more intense at high temperature (and thus cut in some scans). We also note that throughout our XRD plots the peak positions from the observed phases slightly shift between room temperature and $750^{\circ} \mathrm{C}$ due to thermal expansion, which was not corrected for in the plots. (b) Typical SEM image of the grown CNTs from this catalyst evolution. 

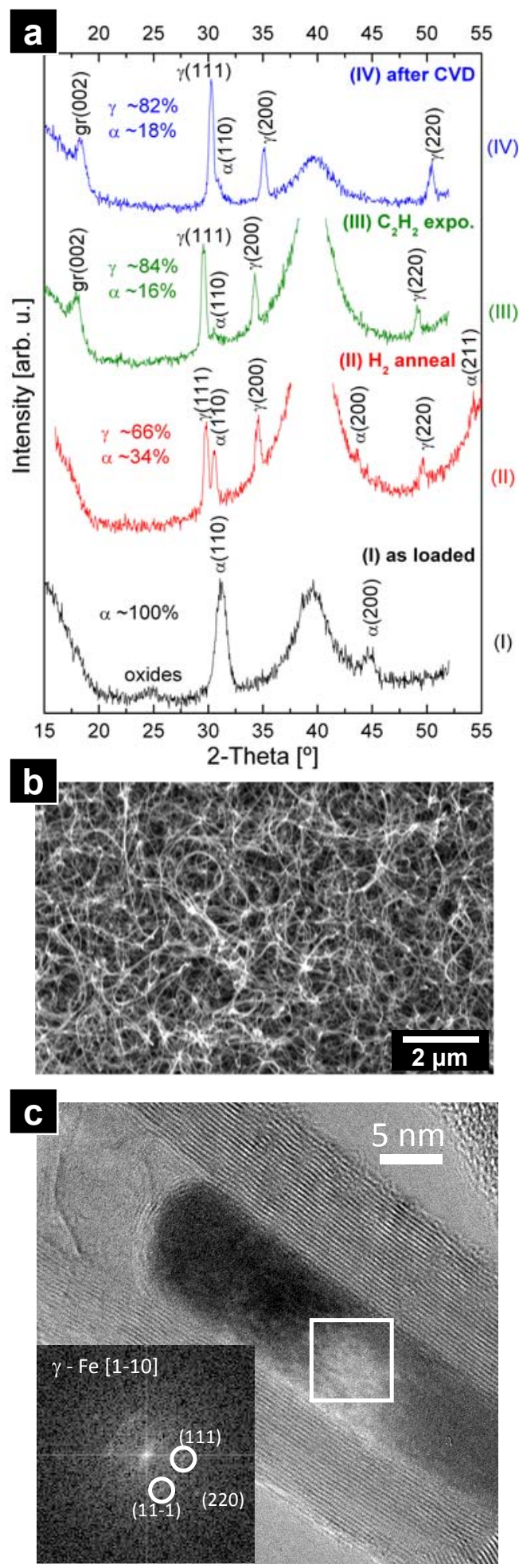

Figure 3: (a) In-situ diffractograms for CVD process steps I-IV. $\gamma$-Fe is the largely dominant phase during growth. ("gr" designates reflections from graphitic material, " $\alpha$ " from $\alpha$-Fe and " $\gamma$ " from $\gamma$-Fe.) (b) Typical SEM image of the grown CNTs from this catalyst evolution. (c) HR-TEM image of a typical catalyst particle from this catalyst evolution. The FFT in the inset shows reflections corresponding to the (111) spacing of $\gamma$-Fe $(0.21 \mathrm{~nm})$ seen along the [1-10] zone axis, confirming that the active particle is $\gamma$-Fe. 

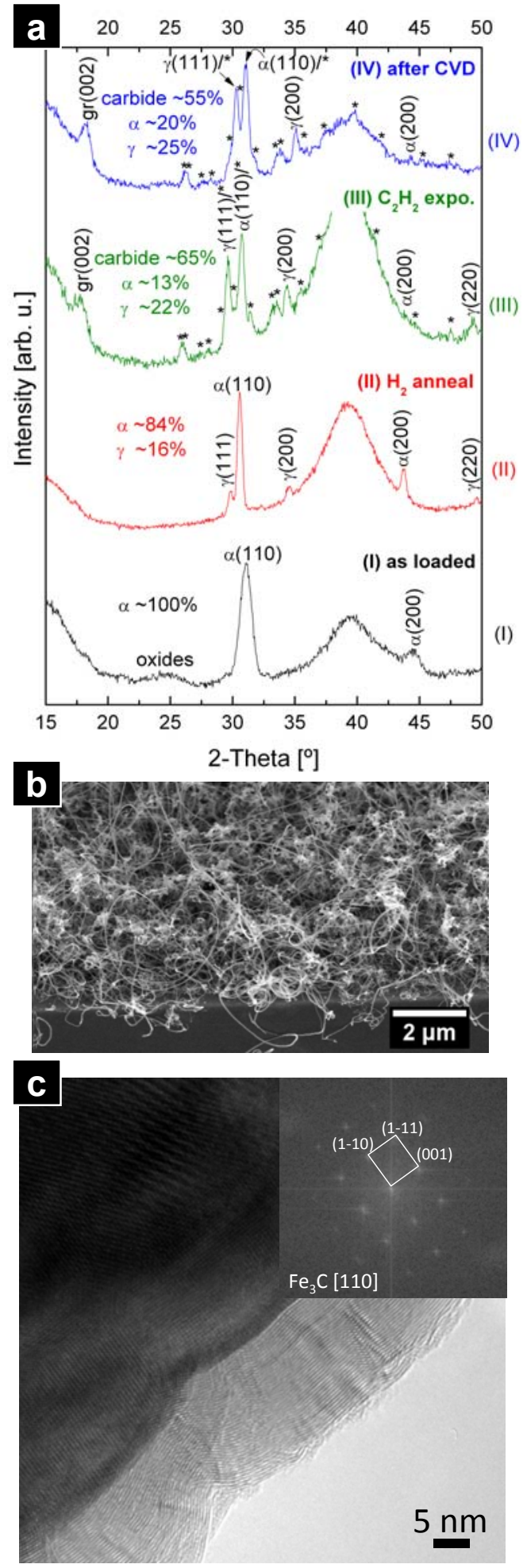

Figure 4: (a) In-situ diffractograms for each CVD process step (I-IV). Predominantly $\alpha$-Fe is detected during pretreatment. $\alpha-\mathrm{Fe}, \gamma-\mathrm{Fe}$ and cementite $\mathrm{Fe}_{3} \mathrm{C}$ are detected during growth, where the carbide is the most dominant phase. ("gr" designates reflections from graphitic material, " $\alpha$ " from $\alpha$-Fe, " $\gamma$ " from $\gamma$-Fe and "*" from $\mathrm{Fe}_{3} \mathrm{C}$.) (b) Typical SEM image of the 
grown CNTs from this catalyst evolution. (c) HR-TEM image of a typical catalyst particle from this catalyst evolution. The FFT in the inset confirms that the active particle is $\mathrm{Fe}_{3} \mathrm{C}$, seen along the [110] zone axis. The reflections indexed in the FFT correspond to lattice spacings of $0.45,0.40$, and $0.30 \mathrm{~nm}$ which match $\mathrm{Fe}_{3} \mathrm{C}(001),(110)$, and (111), respectively. 

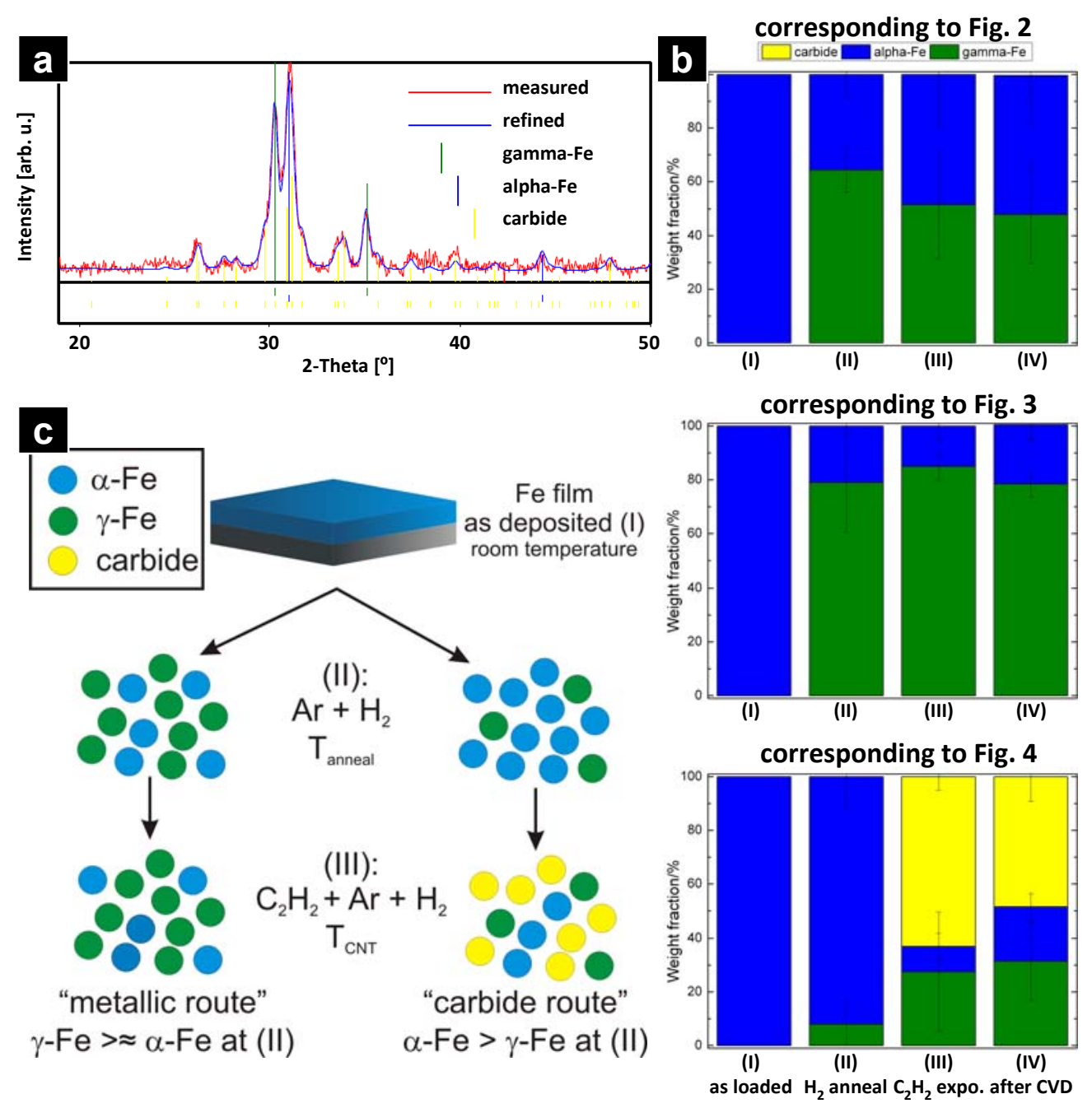

Figure 5: (a) Typical results from Rietveld refinement, exemplified for a carbide-containing sample after CVD. (b) Phase ratios at salient stages of CVD for the different cases exemplified in Figures 2-4. The error bars either indicate the standard deviation of phase composition for repeated observations of the cases or our estimated uncertainty of phase composition determination ( $\pm 5 \mathrm{wt}-\%)$, showing the larger value. (c) Schematic representation of the reaction pathways summarized as "metallic route" and "carbide route". For equi-percentile $\alpha / \gamma$ ratios and high $\gamma$-Fe content growth proceeds via the "metallic" route (without formation of a carbide), while for high $\alpha$-Fe content the appearance of CNTs is accompanied by the formation of cementite $\mathrm{Fe}_{3} \mathrm{C}$ (the "carbide route"). 


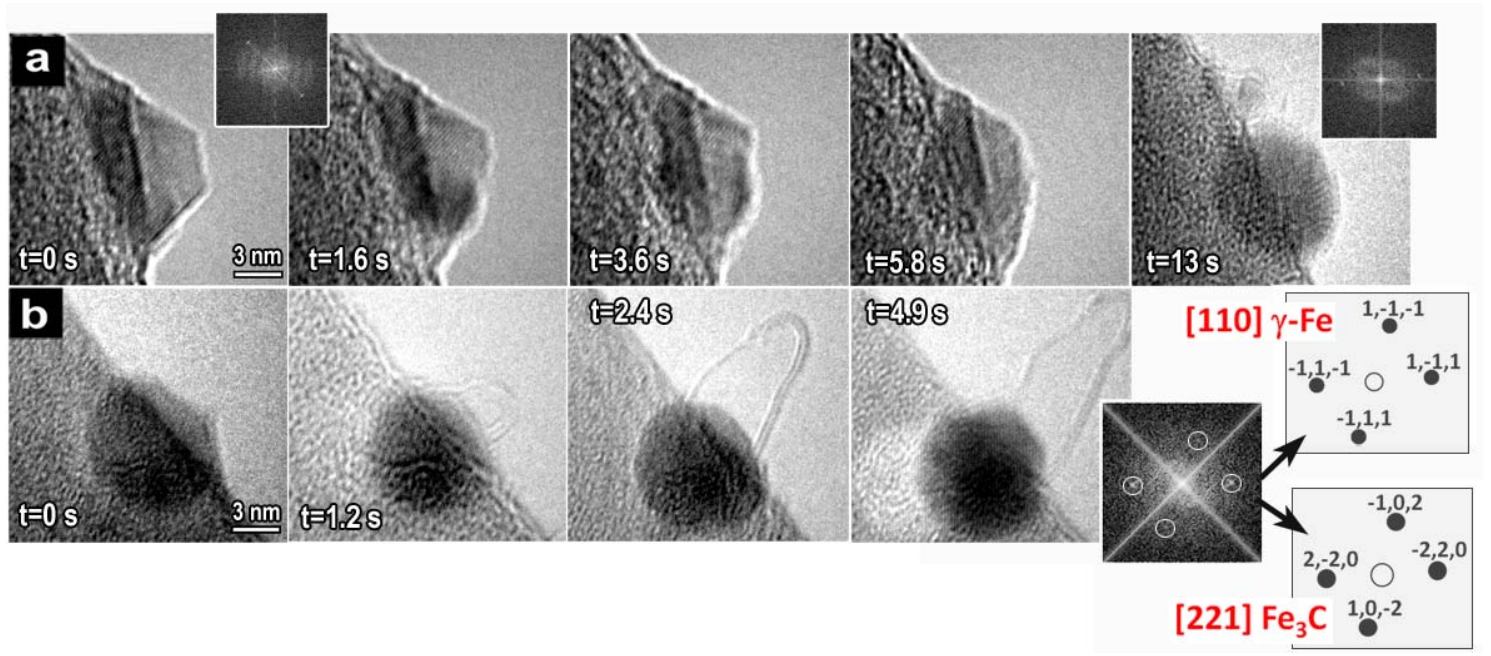

Figure 6: Bright field ETEM image sequences recorded at $\sim 650{ }^{\circ} \mathrm{C}$ in $\sim 10^{-2}$ mbar of $\mathrm{C}_{2} \mathrm{H}_{2}$ showing the restructuring of Fe nanocrystals during (a) reduction and (b) CNT nucleation. The insets show FFTs of the respective particles. Simulated diffraction patterns for $\gamma$-Fe along the [110] zone axis and for cementite $\mathrm{Fe}_{3} \mathrm{C}$ along the [221] zone axis are shown for comparison. The videos were recorded at 9 frames/s and are included in the supporting information (V1, V2). The time difference for each frame relative to the first frame is indicated. 


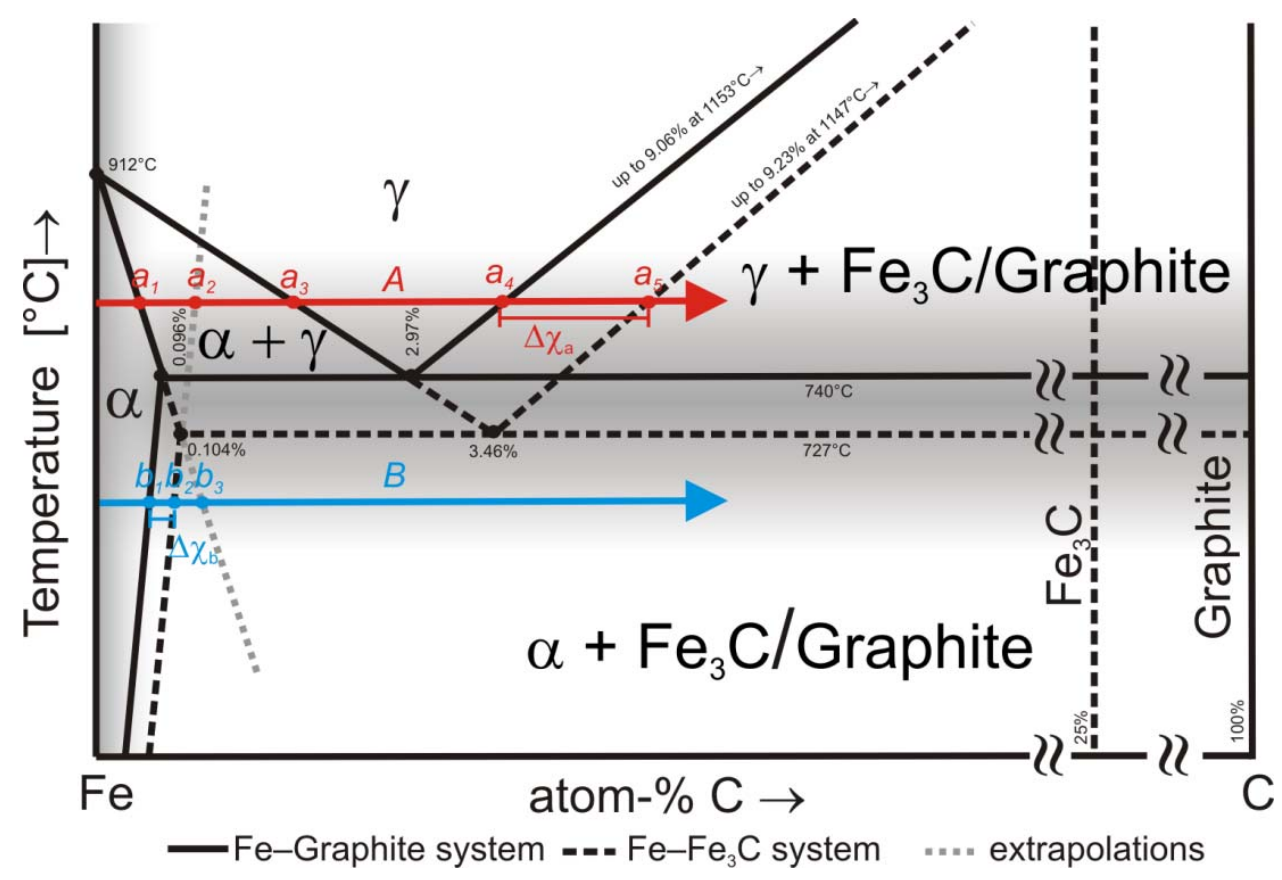

Figure 7: Schematic phase diagram of the Fe-graphite (solid black) and metastable $\mathrm{Fe}_{-} \mathrm{Fe}_{3} \mathrm{C}$ (dashed black) systems (not to scale). Adapted from refs. 42 and 43. Linearly extrapolated phase boundaries are in dashed gray. For the pathways $A$ and $B$ and the shaded areas see the discussion in the main text. 
Table of Contents Image

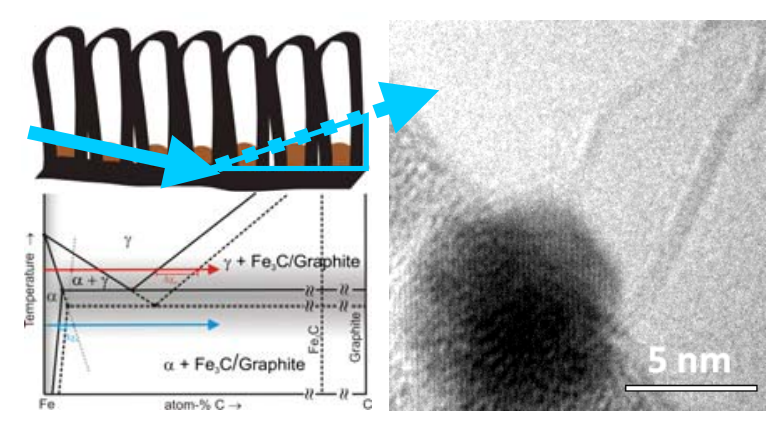

